\title{
Thriving in your career
}

\section{Being open and adaptable to change can help you succeed in your career of choice.}

Choosing a new career takes time and courage, regardless of whether you have just graduated, are becoming increasingly bored at work or have discovered that opportunities for growth are limited in your current position. Staying in a job related to what you studied at university rather than exploring unconventional routes - is a logical course for many individuals. After all, changing careers might seem like too much of a risk in today's volatile economic climate. However, maintaining career momentum when you are unsatisfied with your current position is neither simple nor satisfying.

Many individuals aim to find a job that is related to what they studied at university. For instance, a large percentage of science graduates, especially those with a higher degree, pursue careers in academic or industrial research. Ideally, you should utilize your degree to provide a stepping stone towards your career of choice, although this is easier said than done. Today more than ever, individuals must be adaptable to change. In the book "Who moved my cheese?", Spencer Johnson describes how people deal with the inevitable changes in life. We shouldn't be upset when we are faced with challenges - it's how we deal with those challenges that's important. Moving in a new direction may help us find new opportunities. Refusing to change, in contrast, offers little but comes at the expense of unfulfilled potential.

The key strategy is daring to take unconventional career paths. Your educational background, particularly at $\mathrm{PhD}$ level and above, may seem to narrow your career options, but this is not necessarily true; you can always choose to change, learn new skills and adapt to new roles. The traits that got you to where you are and the skills learned in previous roles will undoubtedly be of use in future positions. For example, the critical analytical skills gained in a scientific research environment qualify you for a wide variety of roles ranging from patent attorney, science policy officer and funding agent through to research commercialization officer, chief executive officer of a start-up company or even a politician. Being flexible and open helps to broaden your horizon.

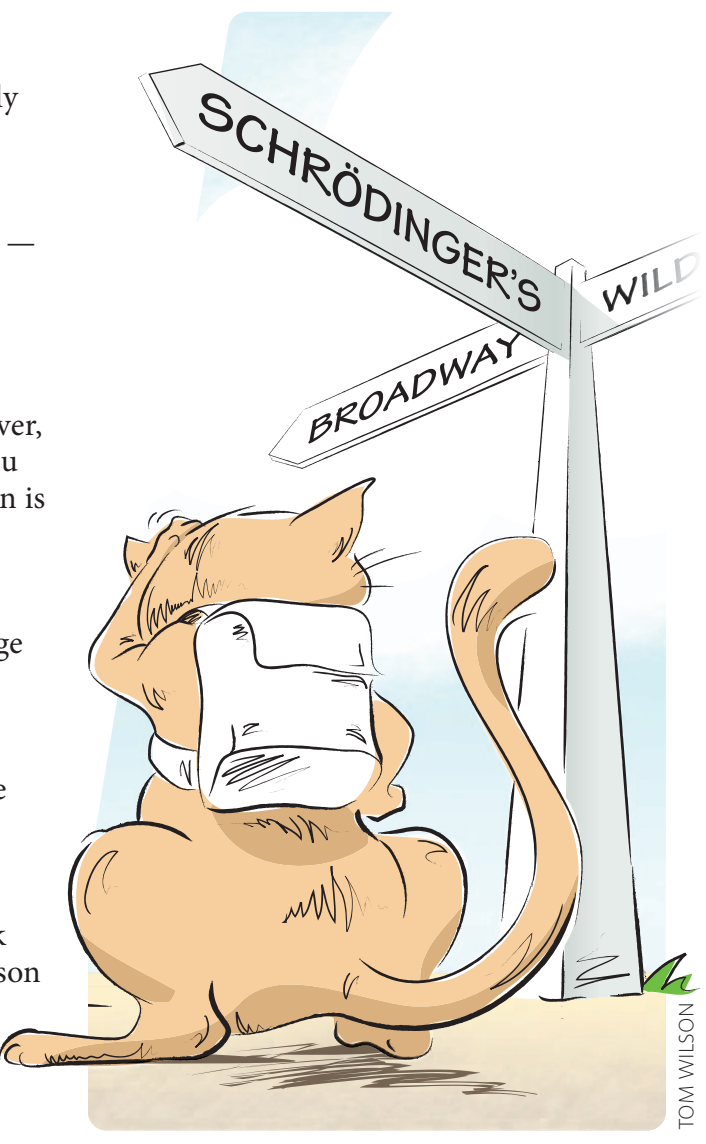

Before taking the plunge, it is important to evaluate your strengths. Many skills, such as management and leadership, time management, communication and computer literacy, are applicable to a wide range of fields. With that said, don't restrict yourself to roles to which you are qualified. Many of us underestimate our potential or suffer from occasional bouts of low selfesteem, and hence we miss the opportunity to stretch our abilities and witness the results. Have the courage to aim high and search for new challenges. After all, "you will never regret what you tried; only what you did not".

Another important aspect to succeeding in your career path is seizing opportunity. But remember, as the 19th century French scientist Louis Pasteur so eloquently put it: "chance favours only the prepared mind." Although chance arguably plays a role in all aspects of life, we must be prepared to recognize opportunities when they present themselves. Preparation for such opportunities is the key to success. Never hesitate to learn new things; few learning experiences will be wasted, and many will lead to new opportunities. Even if your chosen career requires skills or experience you lack, do not despair. There are many ways to gain expertise. Inevitably you may need to sacrifice your free time to gain new skills and experience, such as communication and negotiation, or fluency in a foreign language. You may also need to put in additional hours at the office or volunteer to take on different types of work. When a unique opportunity presents itself, do your best to seize it.

When an opportunity doesn't turn up, find or create it. One cannot merely expect opportunity to drop at one's doorstep. It is essential to be adaptable; expand your professional network and constantly revise your professional progress. Maintaining a diverse range of relationships and building up alliances both help to reinforce your professional network. To this end, skills for developing rapport are indispensable.

Of course, you may sometimes doubt whether a particular opportunity is worth taking on. It would be reckless to take all available opportunities without considering the risks, and it is human nature to question whether even better opportunities may be just around the corner. The key to moving up is to take calculated risks. Consulting former mentors and colleagues who have struggled through the same transition can often help when considering career decisions.

Another option in your career path is the possibility of moving abroad. A career in science often leads to international travel and career options. Be prepared to move from country to country, or even from continent to continent. Such decisions are not made lightly and require many important issues to be considered. Factors include the prospects of the new position, the institution, colleagues, funding, your partner's career, family and friends, children's education, political and social issues, climate, and sometimes even food. The question is: what are your priorities?

The most important point is to be enthusiastic about your job. You are far more likely to be successful in a career that you feel passionate about. After all, if you love what you do, what you do doesn't feel like work. 